\title{
ПСИХОЛОГИЯ ИЗМЕРЕНИЙ
}

\section{А.Насонов}

УДК 621.317

BAK 05.11 .00

\author{
Психология измерений - это парадоксальная игра слов или шутка? \\ Вовсе нет. Это наиболее точное определение причин низкого \\ качества выпускаемой продукции и неудовлетворительных \\ темпов технологического развития. Что имеется в виду? Какие \\ бы современные технологии мы ни использовали, основной \\ производительной силой остается человек. Именно он принимает \\ решение о том, что нужно делать, а без чего можно обойтись. \\ Поэтому психология неизбежно оказывает влияние на процесс \\ создания электронных изделий.
}

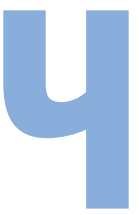

еловеку свойственно двигаться к цели наиболее быстрым и легким путем, то есть минимизировать затраты. Это происходит инстинктивно, потому что заложено в нашу психологию на генетическом уровне. Нам хочется быстрой и легкой победы. Казалось бы, в чем проблема, если цель достигнута?

Однако что считать целью. Инстинктивно, чтобы облегчить достижение положительного результата, человек упрощает цель: ради выработки гормона счастья дофамина можно доказать теорему Пуанкаре, а можно просто в домино выиграть.

Рассмотрим, как это работает в промышленности на примере создания и освоения в производстве нового технически сложного изделия электронной техники. Первый этап-разработка и согласование технического задания (Т3). Не важно, кто его составляет, все равно согласовывать документ будут заказчик и исполнитель. Важно - на что нацелены согласующие стороны.

Цель заказчика в общем случае - получение изделия наилучшего качества за наименьшие деньги. Желание само по себе противоречивое. Хуже всего, что заказчик обычно не обладает знаниями, позволяющими оценить реальную сложность задачи, по этой причине ТЗ в большинстве случаев составляет исполнитель. Он заинтересован получить заказ, а значит, постарается заказчика не пугать, особенно когда есть конкуренты. К тому же Т3 подписывает, как правило, разработчик изделия, и не

\footnotetext{
ООО "Остек-Электро", технический директор,

ostecelectro@ostec-group.ru.
}

факт, что он задумывается обо всех проблемах, возникающих на стадии производства. То есть такие понятия как тестопригодность изделия, соответствие конструкции имеющемуся технологическому оборудованию и прочие якобы мелочи не учитываются.

Можно возразить, что в Т3 есть пункты, определяющие уровень надежности и качества изделия. Зачем еще что-то? Разработчик сам решит, что необходимо для выполнения Т3. Возможно, но только сделает это на опытных образцах, которые сам настроит и проверит. А что будет при запуске в серийное производство - неизвестно. Там другой уровень квалификации регулировщиков, а настраивать изделие так же долго, как опытный образец,- недопустимо. В момент согласования ТЗ и заказчик, и исполнитель, если и понимают все возможные проблемы, то не спешат акцентировать на них внимание. Работает классический подход по принципу "подумаю об этом завтра". А завтра будет поздно, даже не по времени, а по затратам. Стоимость оборудования для тестирования и измерений, как правило, весьма значительная. И если это не учесть при подписании Т3, начнутся рассуждения на тему "как сделать проще". И делают, превращая этап запуска в производство в длительную и весьма нервную эпопею. Зато сколько положительных эмоций, когда получилось. Правда, с дополнительными затратами, в том числе временными.

По факту же сами создали проблему и "героически" с ней справились. Почему так жестко? Потому что отдельного этапа освоения в производстве не должно быть. В Т3 для разработчика должно быть сразу учтено все, что нужно, чтобы он выдал не просто комплект 
конструкторской документации, а абсолютно все необходимое для производства: техпроцесс, оборудование и оснастку для тестирования, программы для автоматов, инструкции, маршруты и т.д. Понятно, что, разрабатывая изделие на таких условиях, он учтет в конструкции технологические особенности производства и требования по тестопригодности, и не надо будет ничего дорабатывать. Предвижу возражение: это что же, конструктор должен отвечать за все? Вообще-то, да. Это не значит, что он должен все сам сделать, нет, но именно он должен обо всем подумать, подключить соисполнителей и определить необходимые ресурсы.

Может выясниться, что трудоемкость разработки приборов и оснастки, необходимых для организации производства и испытаний, превышает трудоемкость разработки изделия. Именно разработки. Одна из широко распространенных иллюзий - все можно купить стандартное, без доработки или дооснащения. Но могут возникать неожиданные проблемы, связанные с отсутствием оборудования, в частности при организации входного контроля.

Например, необходимо организовать входной контроль SMD-резисторов. Имеется подходящий омметр. А как подключаться? Нужен адаптер. Это уже не совсем стандартное оборудование. Не может быть, чтобы такая простая задача превратилась в большую проблему! Но на практике - может. На рынке нельзя найти ничего готового, что можно было бы использовать в производственных условиях, и чтобы это было метрологически состоятельно. Необходимо кельвиновское четырехконтактное подключение, а доступны только приспособления от различных приборов. Но они двухконтактные, следовательно, вносят погрешность при измерении. И это, строго говоря, лабораторные приспособления,

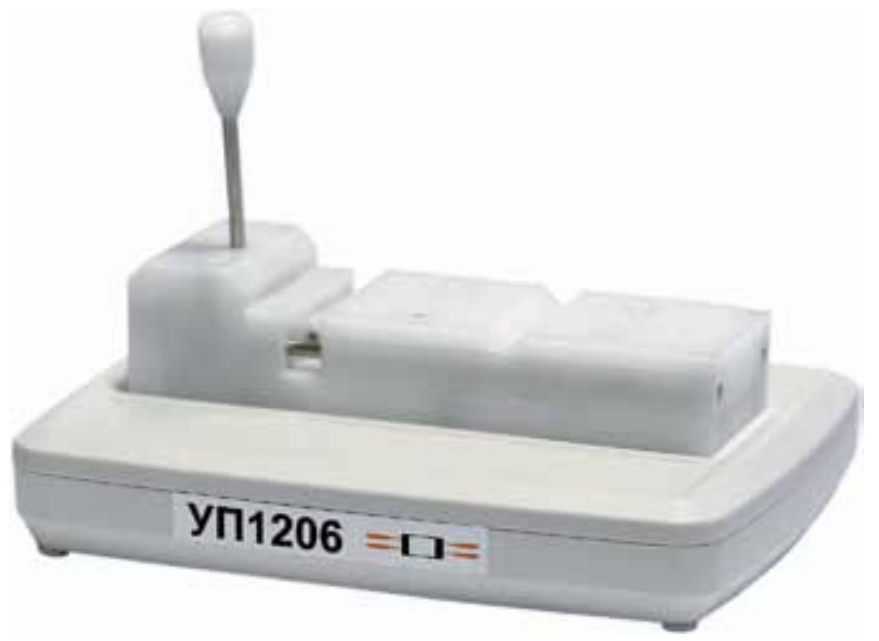

Рис.1. Адаптерное устройство для компонентов 1206 ЛДПА.441532.008 а не промышленное оборудование. Поэтому адаптерные устройства пришлось разрабатывать в России (рис.1).

Типов корпусов у компонентов много, а значит, и адаптеров будет немало. Но ведь речь идет об использовании оборудования на производственном предприятии, значит необходим не омметр с адаптерами, а полноценное рабочее место входного контроля. И это не только стол, стул и приборы, это инструкции, методики и метрологическая аттестация.

Другой пример - входной контроль ферритовых колец. Методика в ТУ на эти изделия предусматривает следующую последовательность действий: на кольцо наматывается пробная катушка, обычно 10 витков; проводится измерение ее индуктивности и по известной формуле, учитывающей размеры кольца, рассчитывается величина начальной магнитной проницаемости. Весьма трудоемкий процесс. А можно использовать специализированный прибор Ш1-23-российское изделие, не имеющее иностранных аналогов (рис.2). Кольцо надо надеть на стержень магнитного датчика и считать значение начальной магнитной проницаемости с экрана.

Многие полагают, что начнут возникать проблемы с комплектующими, тогда и будем решать, зачем заранее об этом думать, тратить время и силы? Психологически такая точка зрения понятна - та же минимизация усилий. Это все равно, что, садясь в лодку, не думать о спасательном жилете. А зачем? Начнем тонуть-подумаем. С входным контролем ситуация еще хуже. Особенно если учесть, что лодки все-таки не часто переворачиваются, а контрафакт и брак есть всегда.

То же наблюдается и при подготовке оборудования для настройки и испытаний изделия. Даже если состав необходимых средств измерений определен, далеко не всегда задумываются о том, как подключаться

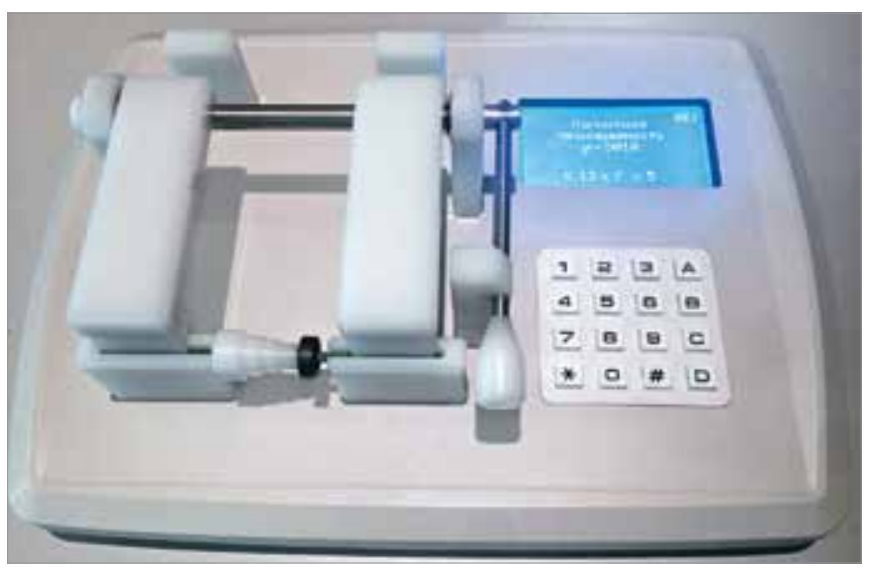

Рис.2. Измеритель параметров ферромагнитных сердечников тороидальной формы типа Ш1-23 ЛДПА.411174.001Ту 


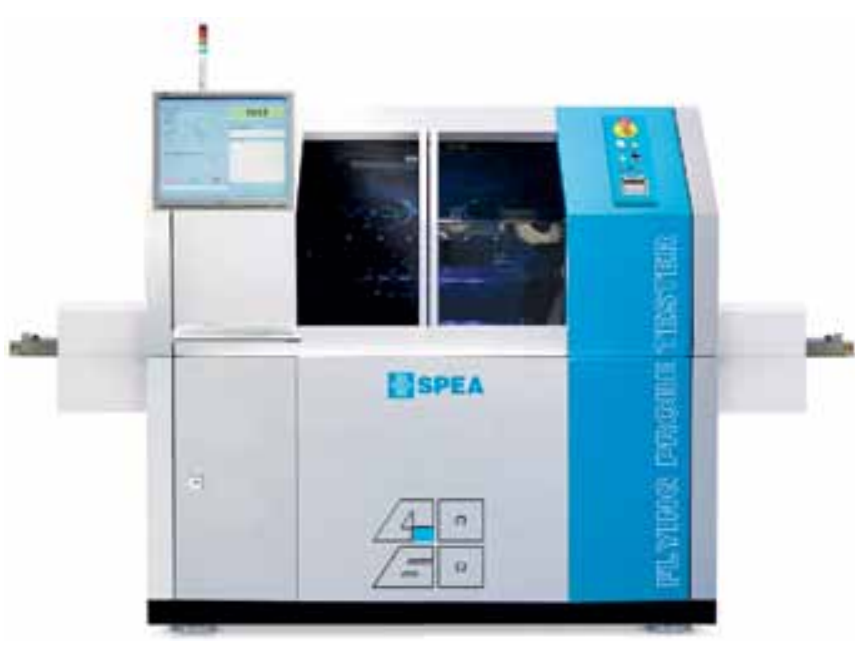

Рис.3. Тестер с "летающими" пробниками SPEA4060

к изделию. А ведь для этого многое необходимо сделать еще при проектировании.

Наиболее наглядный пример - когда плата изделия оснащена компонентами, поддерживающими технологию тестирования JTAG, но соответствующие выводы микросхем не доступны, это делает невозможным использование технологии при производстве изделия. Потом уже ничего нельзя будет сделать, только заново проектировать плату. Придется использовать другие технологии, которые на два порядка дороже, чем JTAG. А всего-то надо было в ТЗ указать требования к оборудованию для тестирования.

Возникает вопрос: а что же делать, если подобный подход к делу в принципе соответствует нормальной психологии человека? Если мы стремимся максимально облегчить путь к цели, надо поставить цель иначе. Например, на предприятии осваивается новое изделие. Цель понятна: разработать и изготовить, получить прибыль. Многие так и поступают. С точки зрения рядового исполнителя цель обычно видна, это нормальный тактический подход. Но должен быть еще и подход стратегический. С этой точки зрения каждое новое изделие должно способствовать развитию предприятия. Должны появляться новые технологии и оборудование. Это вопрос руководства предприятия, существует масса механизмов управления, которыми надо воспользоваться. Например, чтобы в Т3 появились конкретные пункты, предписывающие провести ряд работ для обеспечения последующего производства, необходимо издать соответствующий стандарт предприятия и добиться его выполнения.

Разумеется, на стратегическом уровне принятия решений определяется, какие технологии необходимо осваивать для обеспечения развития предприятия. Так, технологическое оборудование для внутрисхемного тестирования (рис.3) весьма недешево. Но без этой технологии добиться приемлемого на современном уровне качества выпускаемой продукции практически невозможно.

Однако ничего не изменится, если просто приобрести оборудование. Эффективность его использования будет невысокой. Необходимо обучить персонал, причем не только тех, кто будет на нем работать, но прежде всего разработчиков и технологов. Только тогда начнут появляться новые разработки, конструкция которых в полной мере соответствует возможностям современных технологий. И чтобы не искушать соблазном не делать "лишнего", надо четко регламентировать использование технологии на уровне внутризаводских стандартов.

В процессе принятия решений об освоении новых изделий целесообразно привлекать специалистов инжиниринговых компаний. Но не для того, чтобы они выполняли функции арбитра между заказчиком и исполнителем. Их основная роль - использовать свои знания о современных технологиях для помощи в выборе рациональных подходов, учитывающих положительный опыт других предприятий. 